\title{
Improving coronary artery bypass grafting readmission outcomes from 2000 to 2012 in the Medicare population
}

\author{
Christian McNeely, MD, ${ }^{\mathrm{b}}$ Kathleen Kwedar, BS, ${ }^{\mathrm{a}}$ Stephen Markwell, MA, ${ }^{\mathrm{a}}$ and \\ Christina M. Vassileva, MD ${ }^{a, c}$
}

\section{ABSTRACT}

Objective: The study objective was to examine trends in 30-day readmission after coronary artery bypass grafting in the Medicare population over 13 years.

Methods: The study included isolated coronary artery bypass grafting procedures in the Medicare population from January 2000 to November 2012. Comorbidities and causes of readmission were determined using Internal Classification of Diseases, 9th Revision, Clinical Modification diagnostic codes.

Results: The cohort included 1,116,991 patients. Readmission rates decreased from $19.5 \%$ in 2000 to $16.6 \%$ in $2012(P=.0001)$. There was significant improvement across all categories of admission status, age, race, gender, and hospital annual coronary artery bypass grafting volume that were analyzed. Adjusted odds of readmission in 2000 compared with 2012 was 1.28 (95\% confidence interval, 1.24-1.32). Median length of stay for the readmission episode was 5 days, which improved to 4 days by 2012. Hospital mortality during the readmission episode was $2.8 \%$ overall and declined to $2.4 \%$ in $2012(P=.0001)$. The most common primary readmission diagnoses were heart failure $(12.6 \%)$, postoperative wound infection/nonhealing wound (8.9\%), arrhythmias $(6.4 \%)$, and pleural effusions $(3.7 \%)$. Readmission for wound infections/nonhealing wounds decreased significantly over time, from $9.8 \%$ to $6.5 \%(P=.0001)$.

Conclusions: In a large cohort of Medicare patients undergoing coronary artery bypass grafting over 13 years, there was a significant decrease in 30-day readmission rates, a reduction in readmission for wound infections, and reduced mortality during the readmission episode, despite an increase in patient comorbidities. The improvement in readmission rates was seen regardless of patient variables examined. (J Thorac Cardiovasc Surg 2017;154:1288-97)

Readmission after coronary artery bypass grafting (CABG) is common, is associated with worse survival, and has a considerable financial impact. ${ }^{1,2}$ As a result, readmissions, associated with certain conditions and procedures, have prompted national attention. In the last decade, multiple policy decisions have taken place that may be affecting

From the a Division of Cardiothoracic Surgery, Southern Illinois University School of Medicine, Springfield, Ill; ${ }^{\mathrm{b}}$ Department of Medicine, Washington University School of Medicine, St Louis, Mo; and ${ }^{\mathrm{c}}$ Division of Cardiothoracic Surgery, Medical University of South Carolina, Charleston, SC.

Funded by the Division of Cardiothoracic Surgery, Southern Illinois University School of Medicine.

Read at the 96th Annual Meeting of The American Association for Thoracic Surgery, Baltimore, Maryland, May 14-18, 2016.

Received for publication June 16, 2016; revisions received March 23, 2017; accepted for publication April 17, 2017; available ahead of print July 12, 2017.

Address for reprints: Christina M. Vassileva, MD, Division of Cardiothoracic Surgery, Medical University of South Carolina, 114 Doughty St, MSC 295, BM280, Charleston, SC 29425 (E-mail: vassileva@musc.edu).

$0022-5223 / \$ 36.00$

Copyright (c) 2017 by The American Association for Thoracic Surgery

http://dx.doi.org/10.1016/j.jtcvs.2017.04.085

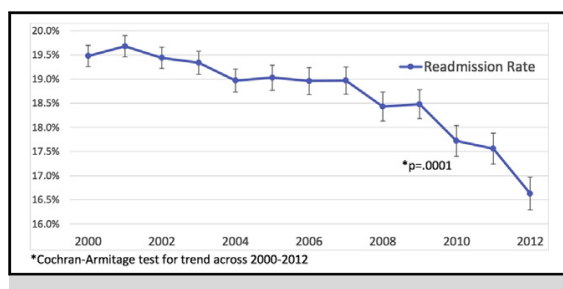

Trends in all-cause, 30-day readmission after CABG.

\section{Central Message \\ Among Medicare beneficiaries from 2000 to 2012, we demonstrate significant improve- ments in readmission rates after $\mathrm{CABG}$, which occurred despite an increase in patient comorbidities.}

\section{Perspective}

Among Medicare beneficiaries, readmission after CABG declined from $19.5 \%$ in 2000 to $16.6 \%$ in 2012 , despite an increase in patient comorbidities. This decline was seen regardless of age, race, gender, and annual CABG volume. Hospital mortality during readmissions also declined. These data indicate improvements in a number of metrics pertinent to the discussion of readmissions after CABG.

See Editorial Commentary page 1298. care. Measures of hospital performance are now partially based on readmission rates, and there is public reporting of those data. ${ }^{3,4}$ The Hospital Readmissions Reduction Program (HRRP) first went into effect in October 2012 after being introduced in 2008. ${ }^{5-7}$

Mortality after CABG has been improving since $2000 .^{8}$ Consequently, it is probable that there have been changes in the postdischarge outcomes of these patients. The trends in outcomes after CABG have not been reported on a national scale. Given that Medicare readmission penalties will take effect in fiscal year 2017 for CABG, we thought an analysis of these trends was timely. Therefore, the purpose of this investigation was to analyze the trends in

Scanning this QR code will take you to the article title page. To view the AATS 2016 Webcast, see the URL next to the video thumbnail.

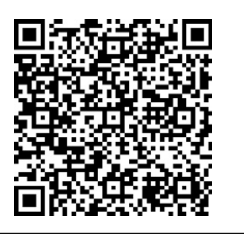




\section{Abbreviations and Acronyms \\ $\mathrm{CABG}=$ coronary artery bypass grafting \\ CI \\ $=$ confidence interval \\ CMS $=$ Centers for Medicare and Medicaid Services \\ COPD $=$ chronic obstructive pulmonary disease \\ HRRP $=$ Hospital Readmissions Reduction Program \\ ICD-9-CM = International Classification if Diseases, 9th Revision, Clinical \\ Modification \\ MI $\quad=$ myocardial infarction \\ $\mathrm{OR} \quad=$ odds ratio}

readmission rates, outcomes, and causes of readmissions after CABG in the Medicare population over a 13-year period from 2000 to 2012.

\section{MATERIALS AND METHODS}

Data were obtained from the Centers for Medicare and Medicaid Services (CMS) using the CMS Virtual Data Research Center (VRDC). The study was approved by our institutional review committee, which waved the requirement for informed consent. No extramural funding was used to support this work. All Medicare beneficiaries aged more than 65 years who underwent isolated CABG from January 2000 to November 2012 were considered for inclusion (Figure 1). They were identified by the International Classification if Diseases, 9th Revision, Clinical Modification (ICD-9-CM) procedure codes $36.1 \mathrm{X}$, where $\mathrm{X}$ represents any number. Nonisolated CABG cases were identified and excluded using the same methodology used by the CMS. ${ }^{9}$ Specifically, we excluded the following concomitant procedure groups: valve procedures, atrial or ventricular septal defects, congenital anomalies, heart transplants, aorta or other noncardiac arterial bypass procedures, and head, neck, or intracranial vascular procedures. Cases were excluded if patients had less than 12 months of Part A coverage before CABG or if patients were enrolled in any Health Maintenance Organization at the time of CABG. In addition, patients who were no longer covered under Part A or who were in an Health Maintenance Organization during the 30-day period after their CABG were excluded. We also excluded patients coming from hospitals that performed less than $5 \mathrm{CABG}$ procedures in a given year, because these might have represented a coding error. Patients who died during the $\mathrm{CABG}$ admission or who were discharged against medical advice were excluded. We also excluded those who had a prior CABG within 30 days of their index admission.

Comorbidities were determined using the ICD-9-CM diagnostic codes from all hospitalizations occurring in the 1-year period leading up to and including the admission for CABG, with the exception of stroke, atrial fibrillation, and renal failure, which did not include the index CABG admission. Comorbidities selected for inclusion were largely consistent with the CMS methodology report. ${ }^{9}$ Acute myocardial infarction (MI) was based on a primary diagnosis during the CABG admission. Atrial fibrillation determination was based on documentation before the index visit using the Chronic Condition Warehouse earliest indication of atrial fibrillation and the primary and secondary ICD-9-CM diagnostic codes from hospitalizations during the 12-month period before the index admission. $\mathrm{CABG}$ was coded as emergency if the operation was performed on the day of admission and the admission source was one of the following: transfer from another hospital, transfer from a skilled nursing facility, transfer

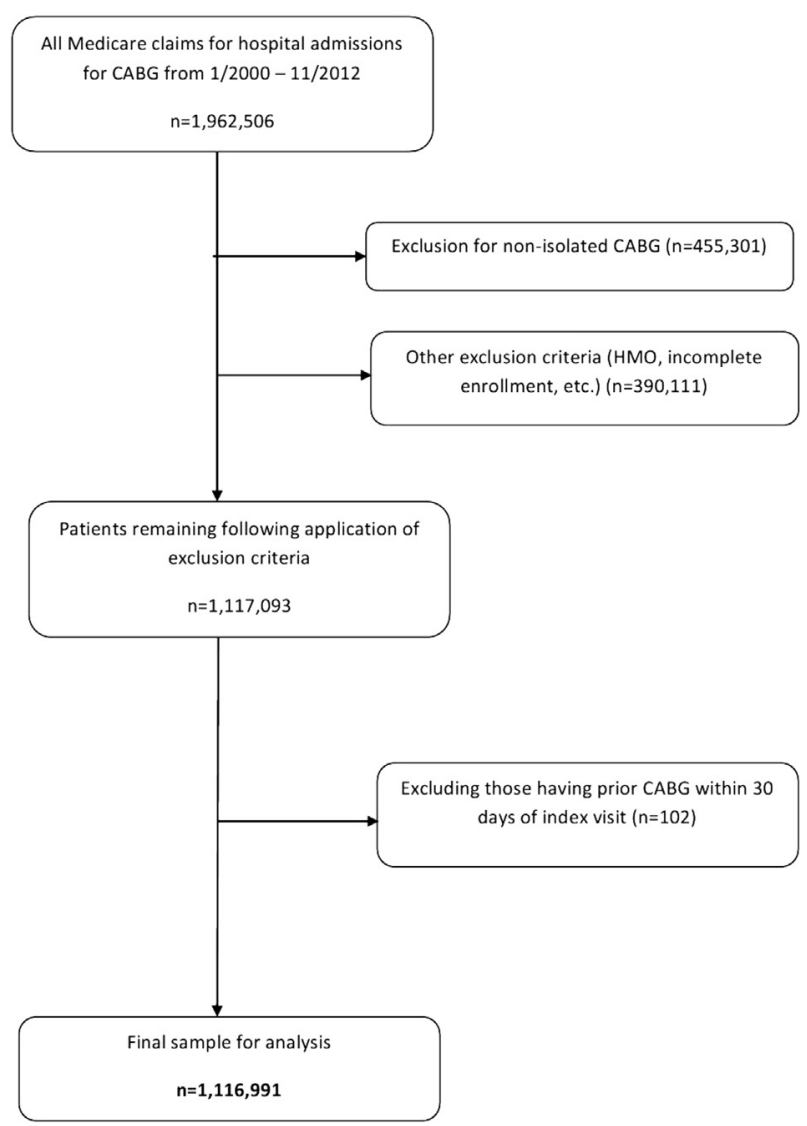

FIGURE 1. Flowchart of patient selection. $C A B G$, Coronary artery bypass grafting; $H M O$, Health Maintenance Organization.

from another health care facility, or the noted emergency department charge amount was greater than 0 . If CABG was performed after the admission date but during the same hospital stay, then the status was coded as urgent. CABG that occurred on the day of admission with the patient coming from home was coded as elective. Annual CABG volume was determined for each hospital and categorized as less than 50, 50 to 100,101 to 200 , or greater than $200 \mathrm{CABG}$ per year.

All MedPar records were examined to determine readmissions that occurred within 30 days of discharge after CABG. All-cause, 30-day readmission was defined as an admission to an acute care hospital for any reason within 30 days of discharge after the index hospitalization. For patients who were transferred to an acute care facility, the 30-day window started after discharge from the acute care facility and the readmission was linked back to the hospital in which the CABG was performed. If a patient was readmitted within 30 days and underwent another $\mathrm{CABG}$, the second $\mathrm{CABG}$ (the one during the readmission) was counted as a complication and not as an index procedure. Analyses examined only the first readmission that occurred within 30 days, and not subsequent admissions, which is the same methodology as the CMS.

Chi-square tests of independence were used to compare baseline characteristics between patients with a readmission within 30 days and patients without a readmission. A Wilcoxon rank-sum test was used to compare age by those who were readmitted versus those without readmission. To assess trends in readmissions over time, Cochran-Armitage trend tests were used and $P$ values are reported. To produce adjusted odds ratios (ORs) for 30-day readmission and hospital death, hierarchical logistic regression was used to account for clustering within hospitals, using the variables outlined in Table 1, year (as a categoric variable), and hospital CABG volume group. 
TABLE 1. Longitudinal changes in baseline characteristics

\begin{tabular}{|c|c|c|c|c|c|c|c|c|c|}
\hline Characteristic & Overall & 2000 & 2002 & 2004 & 2006 & 2008 & 2010 & 2012 & $P$ value* \\
\hline$N$ & $1,116,991$ & 123,721 & 12,1005 & 102,872 & 81,965 & 66,968 & 59,302 & 46,699 & \\
\hline Age, y, median & 74 & 74 & 74 & 74 & 74 & 73 & 73 & 73 & \\
\hline Female & $32.5 \%$ & $34.5 \%$ & $34.0 \%$ & $33.0 \%$ & $32.0 \%$ & $31.5 \%$ & $29.8 \%$ & $29.3 \%$ & .0001 \\
\hline White & $90.5 \%$ & $91.9 \%$ & $91.0 \%$ & $90.0 \%$ & $90.2 \%$ & $90.2 \%$ & $89.8 \%$ & $89.2 \%$ & .0001 \\
\hline \multicolumn{10}{|l|}{ Admission } \\
\hline Elective & $29.1 \%$ & $25.5 \%$ & $26.8 \%$ & $28.3 \%$ & $30.9 \%$ & $31.5 \%$ & $32.8 \%$ & $32.2 \%$ & .0001 \\
\hline Urgent & $67.6 \%$ & $71.4 \%$ & $70.1 \%$ & $68.2 \%$ & $65.8 \%$ & $65.0 \%$ & $63.7 \%$ & $64.1 \%$ & .0001 \\
\hline Emergency & $3.3 \%$ & $3.1 \%$ & $3.1 \%$ & $3.5 \%$ & $3.2 \%$ & $3.5 \%$ & $3.5 \%$ & $3.8 \%$ & .0001 \\
\hline Acute MI & $21.7 \%$ & $20.3 \%$ & $21.4 \%$ & $21.2 \%$ & $21.0 \%$ & $22.1 \%$ & $22.8 \%$ & $26.0 \%$ & .0001 \\
\hline Prior MI & $9.8 \%$ & $10.8 \%$ & $9.4 \%$ & $8.3 \%$ & $7.3 \%$ & $7.6 \%$ & $11.1 \%$ & $17.3 \%$ & .0001 \\
\hline Prior PCI & $7.1 \%$ & $8.0 \%$ & $8.0 \%$ & $6.1 \%$ & $5.6 \%$ & $6.1 \%$ & $7.0 \%$ & $8.7 \%$ & .0001 \\
\hline Prior CABG & $2.2 \%$ & $3.2 \%$ & $2.8 \%$ & $2.1 \%$ & $1.7 \%$ & $1.6 \%$ & $1.6 \%$ & $1.9 \%$ & .0001 \\
\hline Hx heart valve & $0.2 \%$ & $0.2 \%$ & $0.2 \%$ & $0.2 \%$ & $0.2 \%$ & $0.1 \%$ & $0.2 \%$ & $0.4 \%$ & .0001 \\
\hline Hx hypertension & $60.3 \%$ & $55.7 \%$ & $57.0 \%$ & $57.0 \%$ & $53.1 \%$ & $56.6 \%$ & $71.7 \%$ & $84.4 \%$ & .0001 \\
\hline Hx diabetes & $29.9 \%$ & $27.6 \%$ & $27.8 \%$ & $27.7 \%$ & $26.7 \%$ & $27.6 \%$ & $35.9 \%$ & $44.2 \%$ & .0001 \\
\hline Hx PVD & $4.3 \%$ & $3.9 \%$ & $4.0 \%$ & $3.9 \%$ & $3.8 \%$ & $3.8 \%$ & $5.0 \%$ & $7.4 \%$ & .0001 \\
\hline Hx stroke/TIA & $4.1 \%$ & $4.4 \%$ & $4.2 \%$ & $3.9 \%$ & $3.6 \%$ & $4.0 \%$ & $4.1 \%$ & $4.6 \%$ & .4553 \\
\hline Hx heart failure & $21.8 \%$ & $22.0 \%$ & $22.2 \%$ & $22.1 \%$ & $22.4 \%$ & $17.4 \%$ & $21.1 \%$ & $24.9 \%$ & .8849 \\
\hline Hx COPD & $17.6 \%$ & $16.9 \%$ & $18.1 \%$ & $18.6 \%$ & $18.8 \%$ & $11.9 \%$ & $15.7 \%$ & $20.2 \%$ & .0079 \\
\hline Hx renal failure/ESRD & $3.4 \%$ & $1.8 \%$ & $2.0 \%$ & $2.4 \%$ & $4.5 \%$ & $3.9 \%$ & $5.5 \%$ & $7.2 \%$ & .0001 \\
\hline Hx atrial fibrillation & $9.0 \%$ & $7.7 \%$ & $9.3 \%$ & $8.8 \%$ & $8.6 \%$ & $8.9 \%$ & $10.1 \%$ & $10.7 \%$ & .0001 \\
\hline
\end{tabular}

$M I$, Myocardial infarction; $P C I$, percutaneous coronary intervention; $C A B G$, coronary artery bypass grafting; $H x$, history; $P V D$, peripheral vascular disease; $T I A$, transient ischemic attack; COPD, chronic obstructive pulmonary disease; ESRD, end-stage renal disease. *Cochran-Armitage test for trend across $2000-2012$.

Hospital was treated as a random effect. Two separate models were fit to predict both readmission and hospital death using these variables. The model used to predict hospital death was only of patients who were readmitted. The variables and their adjusted ORs for each of the models are reported in Tables 2 and 3. All analyses were performed using SAS Enterprise Guide v7.1 (2014, SAS Institute Inc, Cary, NC).

\section{RESULTS}

The study cohort included 1,116,991 Medicare beneficiaries aged 65 years and older who underwent isolated CABG (Figure 1). Overall, the 30-day readmission rate was $18.9 \%$. Readmission rates declined across the years (2000 - 19.5\% to $2012-16.6 \% ; P=.0001$ ) (Figure 2). The prevalence of most comorbidities increased during the course of the study period, with the exception of prior $\mathrm{CABG}$. The prevalence of female gender and white race decreased during the study (Table 1 ). When readmission rates were adjusted to account for differing patient comorbidity profiles over time, the odds of readmission for patients in 2000 were $28 \%$ greater than for patients in 2012 (OR for readmission, $1.28 ; 95 \%$ confidence interval [CI], 1.24-1.32). The majority (70.4\%) of patients who had a readmission within 30 days experienced only 1 readmission, $23.4 \%$ had 2 readmissions, $4.6 \%$ had 3 readmissions, and the remaining $1.6 \%$ had 4 or more readmissions within 30 days after CABG. The median time to first readmission was 9 days (interquartile range, 4-16). The median length of stay for the readmission episode was 5 days (interquartile range, 3-8) overall and 4 days from 2009 to 2012 (Table 4). A minority of patients had percutaneous coronary intervention $(1.3 \%)$ or CABG $(0.1 \%)$ during readmission. Hospital mortality associated with readmission was $2.8 \%$ overall and declined over the study period $(2000-2.8 \%$ to $2012-2.4 \%), P=.0001$ (Table 4 ).

We compared the patient characteristics of patients readmitted with those who were not. Readmitted patients were more likely to be female ( $39 \%$ vs $31 \%$ ), to have had an acute MI during their index admission ( $25 \%$ vs $20.9 \%$ ), and to have a history of heart failure ( $30.9 \%$ vs $19.7 \%$ ), renal failure $(5.9 \%$ vs $2.8 \%)$, chronic obstructive pulmonary disease (COPD) $(22.5 \%$ vs $16.5 \%)$, and atrial fibrillation $(12.4 \%$ vs $8.2 \%$ ) (Table 5). Adjusted ORs for their impact on readmission were reported from the hierarchical logistic regression model (Table 2). Of the factors examined, those associated with the greatest odds of 30-day readmission were a history of renal failure (OR, 1.61; 95\% CI, 1.57-1.64), history of heart failure (OR, $1.46 ; 95 \% \mathrm{CI}, 1.44-1.48)$, history of atrial fibrillation (OR, $1.40 ; 95 \% \mathrm{CI}, 1.38-1.42)$, history of COPD (OR, 1.36 ; $95 \%$ CI, $1.35-1.38$ ), age 80 years or more (OR, 1.36 ; $95 \%$ CI, 1.34-1.38), female gender (OR, 1.34; 95\% 
TABLE 2. Adjusted odds ratios for risk of 30-day readmission stratified by patient/hospital characteristics and year

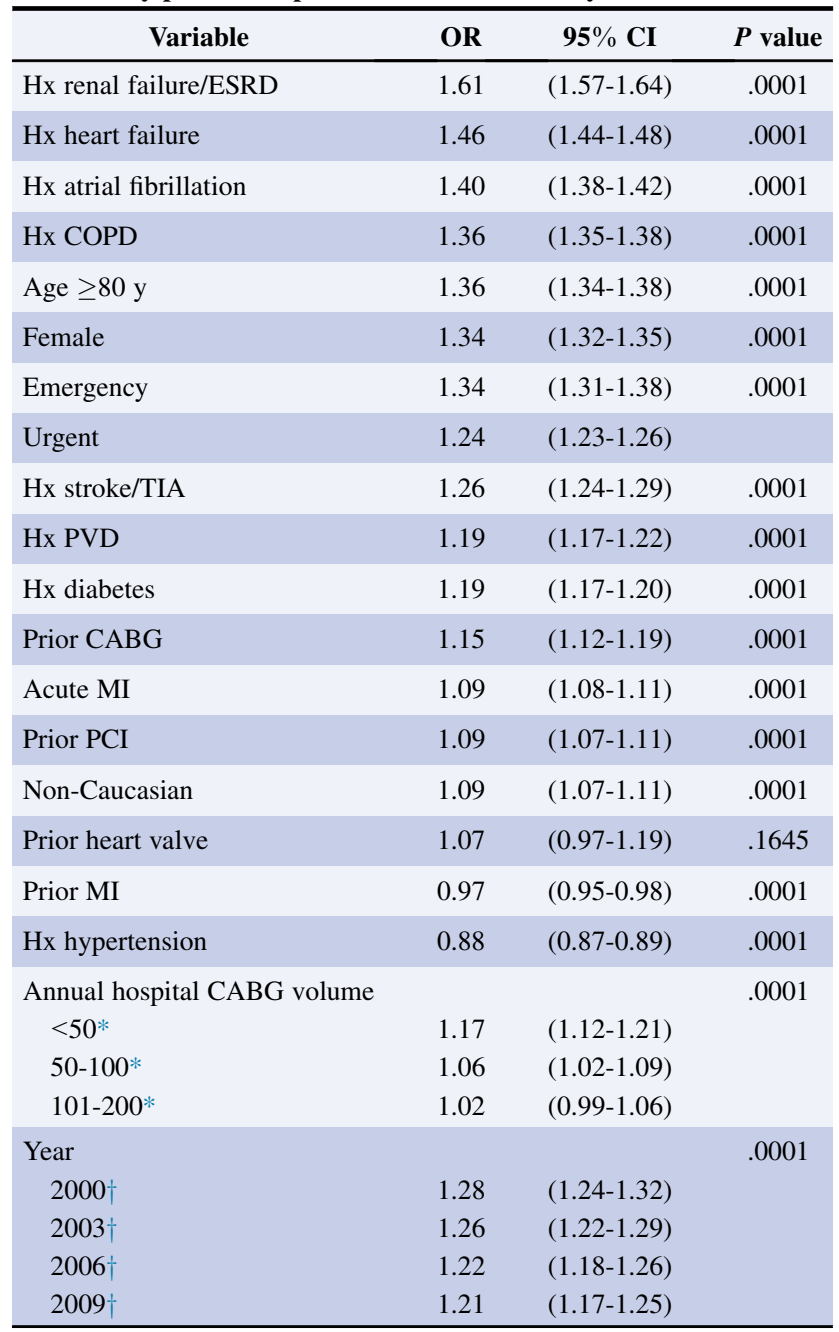

$O R$, Odds ratio; $C I$, confidence interval; $H x$, history; $E S R D$, end-stage renal disease; $C O P D$, chronic obstructive pulmonary disease; TIA, transient ischemic attack; $P V D$, peripheral vascular disease; $C A B G$, coronary artery bypass grafting; $M I$, myocardial infarction; $P C I$, percutaneous coronary intervention. * Relative to $>200$. $†$ Relative to 2012.

CI, 1.32-1.35), and nonelective admission status (OR, 1.34; $95 \%$ CI, $1.31-1.38$ for emergency, OR, 1.24 ; $95 \%$ CI, 1.23 1.26 for urgent).

Trends in principle readmission diagnoses are presented in Table 6. The most common reasons for readmission in declining frequency were congestive heart failure in $12.6 \%$ of patients, postoperative wound infection or nonhealing wound in $8.9 \%$ of patients, cardiac arrhythmias in $6.4 \%$ of patients, pleural effusion in $3.7 \%$ of patients, chronic ischemic heart disease in $3.6 \%$ of patients, and pneumonia in $3.2 \%$ of patients. Readmission for wound complications/ nonhealing had the largest magnitude of change during the study period, decreasing from $9.8 \%$ to $6.5 \%$.

We also examined the impact of annual hospital volume, acute $\mathrm{MI}$ at the time of index $\mathrm{CABG}$, age $(<80$
TABLE 3. Adjusted odds ratios for risk of hospital death during readmission after coronary artery bypass grafting stratified by patient/hospital characteristics and year

\begin{tabular}{|c|c|c|c|}
\hline Variable & OR & $95 \%$ CI & $P$ value \\
\hline Hx heart failure & 1.60 & $(1.52-1.69)$ & .0001 \\
\hline Hx renal failure/ESRD & 1.59 & $(1.45-1.75)$ & .0001 \\
\hline Age $\geq 80 y$ & 1.50 & $(1.42-1.59)$ & .0001 \\
\hline Hx atrial fibrillation & 1.30 & $(1.21-1.39)$ & .0001 \\
\hline Hx COPD & 1.29 & $(1.21-1.36)$ & .0001 \\
\hline Acute MI & 1.24 & $(1.17-1.32)$ & .0001 \\
\hline Hx PVD & 1.13 & $(1.01-1.26)$ & .0313 \\
\hline Emergency & 1.12 & $(0.97-1.29)$ & .2859 \\
\hline Urgent & 1.02 & $(0.95-1.09)$ & \\
\hline Prior CABG & 1.09 & $(0.93-1.27)$ & .3148 \\
\hline Hx stroke/TIA & 1.08 & $(0.97-1.21)$ & .1794 \\
\hline Non-Caucasian & 1.04 & $(0.96-1.13)$ & .3472 \\
\hline Female & 1.03 & $(0.98-1.08)$ & .3047 \\
\hline Hx diabetes & 0.92 & $(0.87-0.98)$ & .006 \\
\hline Prior heart valve & 0.86 & $(0.51-1.44)$ & .5605 \\
\hline Prior MI & 0.82 & $(0.74-0.90)$ & .0001 \\
\hline Prior PCI & 0.78 & $(0.69-0.87)$ & .0001 \\
\hline Hx hypertension & 0.70 & $(0.66-0.74)$ & .0001 \\
\hline $\begin{array}{l}\text { Annual hospital CABG volume } \\
<50^{*} \\
50-100^{*} \\
101-200^{*}\end{array}$ & $\begin{array}{l}1.03 \\
0.99 \\
1.03\end{array}$ & $\begin{array}{l}(0.91-1.16) \\
(0.91-1.08) \\
(0.96-1.10)\end{array}$ & .7925 \\
\hline $\begin{array}{l}\text { Year } \\
2000 \dagger \\
2003 \dagger \\
2006 \dagger \\
2009 \dagger\end{array}$ & $\begin{array}{l}1.14 \\
1.19 \\
1.06 \\
0.89\end{array}$ & $\begin{array}{l}(0.97-1.35) \\
(1.01-1.41) \\
(0.89-1.26) \\
(0.73-1.07)\end{array}$ & .0001 \\
\hline
\end{tabular}

$O R$, Odds ratio; $C I$, confidence interval; $H x$, history; $E S R D$, end-stage renal disease; $C O P D$, chronic obstructive pulmonary disease; $M I$, myocardial infarction; $P V D$, peripheral vascular disease; $C A B G$, coronary artery bypass grafting; $T I A$, transient ischemic attack; PCI, percutaneous coronary intervention. *Relative to $>200$. $\dagger$ Relative to 2012.

and $\geq 80$ years), gender, and race on hospital readmission. Trends in readmission rate stratified by various index

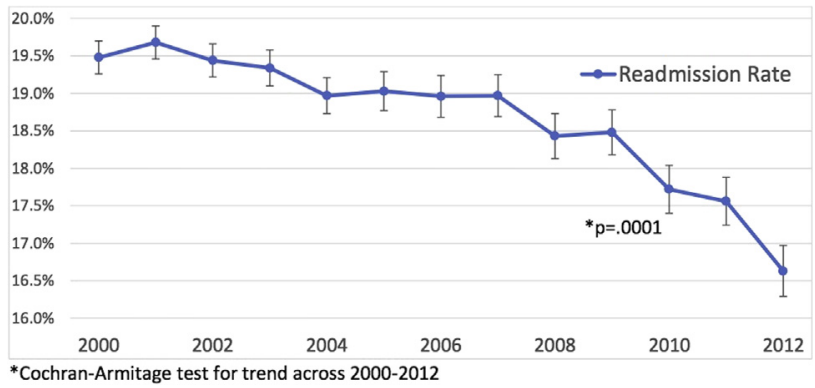

FIGURE 2. Trends in all-cause, 30-day readmission after CABG with $95 \%$ CIs. 
TABLE 4. Readmission-related outcomes

\begin{tabular}{lrrrrrrrrr}
\hline \multicolumn{1}{c}{ Outcome } & Overall & $\mathbf{2 0 0 0}$ & $\mathbf{2 0 0 2}$ & $\mathbf{2 0 0 4}$ & $\mathbf{2 0 0 6}$ & $\mathbf{2 0 0 8}$ & $\mathbf{2 0 1 0}$ & $\mathbf{2 0 1 2}$ & $\boldsymbol{P}$ value* \\
\hline No. of readmissions & 211,147 & 24,096 & 23,522 & 19,514 & 15,540 & 12,340 & 10,507 & 7767 & \\
LOS & $5(3-8)$ & $5(3-8)$ & $5(3-9)$ & $5(3-8)$ & $5(3-8)$ & $5(3-8)$ & $4(2-8)$ & $4(2-8)$ & .0101 \\
\hline Hospital mortality & $2.8 \%$ & $2.8 \%$ & $3.3 \%$ & $2.8 \%$ & $2.8 \%$ & $2.5 \%$ & $2.4 \%$ & $2.4 \%$ & .0001 \\
Heart catheterization/angiography & $3.0 \%$ & $3.0 \%$ & $3.1 \%$ & $3.2 \%$ & $2.7 \%$ & $3.2 \%$ & $3.3 \%$ & $3.1 \%$ & .3353 \\
PCI (PTCA or stent) & $1.3 \%$ & $1.0 \%$ & $1.2 \%$ & $1.4 \%$ & $1.4 \%$ & $1.5 \%$ & $1.5 \%$ & $1.6 \%$ & .0001 \\
Revascularization, CABG & $0.1 \%$ & $0.1 \%$ & $0.1 \%$ & $0.1 \%$ & - & - & - & - & .7514 \\
Discharge destination, home & $70.0 \%$ & $74.3 \%$ & $72.0 \%$ & $69.7 \%$ & $69.1 \%$ & $67.9 \%$ & $67.4 \%$ & $66.0 \%$ & .0001 \\
Discharge destination, rehabilitation & $3.2 \%$ & - & $2.3 \%$ & $3.3 \%$ & $3.0 \%$ & $3.5 \%$ & $3.7 \%$ & $4.0 \%$ & .0001 \\
Discharge destination, nursing home & $15.8 \%$ & $12.7 \%$ & $13.3 \%$ & $15.8 \%$ & $17.2 \%$ & $17.6 \%$ & $18.4 \%$ & $18.5 \%$ & .0001 \\
\hline
\end{tabular}

LOS, Length of stay; $P C I$, percutaneous coronary intervention; $P T C A$, percutaneous transluminal coronary angioplasty; $C A B G$, coronary artery bypass grafting. *Cochran-Armitage test for trend across 2000-2012.

procedure variables are shown in Table 7. There was significant improvement across all of the aforementioned categories examined over the course of this study $(P<.05$ for all). Trends in 30-day readmission by annual hospital CABG volume are shown in Figure 3. Adjusted readmission

TABLE 5. Baseline characteristics stratified by readmission status

\begin{tabular}{|c|c|c|c|c|}
\hline Characteristic & Overall & No readmission & Readmission & $\begin{array}{c}P \\
\text { i value }\end{array}$ \\
\hline $\mathrm{N}$ & $1,116,991$ & 905,844 & 211,147 & \\
\hline $\begin{array}{l}\text { Age, } y, \\
\text { median (IQR) }\end{array}$ & $74(70-80)$ & 73 (69-78) & 75 (70-79) & .0001 \\
\hline Female & $32.5 \%$ & $31.0 \%$ & $39.0 \%$ & .0001 \\
\hline White & $90.5 \%$ & $90.8 \%$ & $89.2 \%$ & .0001 \\
\hline \multicolumn{5}{|l|}{ Admission } \\
\hline Elective & $29.0 \%$ & $30.3 \%$ & $23.6 \%$ & .0001 \\
\hline Urgent & $67.6 \%$ & $66.5 \%$ & $72.6 \%$ & .0001 \\
\hline Emergency & $3.3 \%$ & $3.2 \%$ & $3.7 \%$ & .0001 \\
\hline Acute MI & $21.6 \%$ & $20.9 \%$ & $25.0 \%$ & .0001 \\
\hline Prior MI & $9.8 \%$ & $9.8 \%$ & $9.6 \%$ & .0019 \\
\hline Prior PCI & $7.1 \%$ & $6.9 \%$ & $8.1 \%$ & .0001 \\
\hline Prior $\mathrm{CABG}$ & $2.2 \%$ & $2.1 \%$ & $2.7 \%$ & .0001 \\
\hline Hx heart valve & $0.2 \%$ & $0.2 \%$ & $0.3 \%$ & .0001 \\
\hline Hx hypertension & $60.2 \%$ & $60.9 \%$ & $57.6 \%$ & .0001 \\
\hline Hx diabetes & $29.9 \%$ & $29.1 \%$ & $33.4 \%$ & .0001 \\
\hline Hx PVD & $4.3 \%$ & $4.1 \%$ & $5.3 \%$ & .0001 \\
\hline Hx stroke/TIA & $4.0 \%$ & $3.7 \%$ & $5.4 \%$ & .0001 \\
\hline Hx heart failure & $21.8 \%$ & $19.7 \%$ & $30.9 \%$ & .0001 \\
\hline Hx COPD & $17.6 \%$ & $16.5 \%$ & $22.5 \%$ & .0001 \\
\hline $\begin{array}{l}\text { Hx renal } \\
\quad \text { failure/ESRD }\end{array}$ & $3.4 \%$ & $2.8 \%$ & $5.9 \%$ & .0001 \\
\hline Hx atrial fibrillation & $9.0 \%$ & $8.2 \%$ & $12.4 \%$ & .0001 \\
\hline
\end{tabular}

rates were significantly related to annual hospital CABG volume (OR, 1.17; 95\% CI, 1.12-1.21, for volume $<50$ cases/year compared with annual hospital CABG volume $>200$ ). Qualitatively, this gap between centers of differing volumes appeared to narrow over time, although this was not formally assessed.

Many of the top factors that predicted readmission also were predictors for death during readmission. The most significant factors predictive of death during readmission were the following: history of heart failure (OR, 1.60; $95 \%$ CI, 1.52-1.69), history of renal failure (OR, 1.59; $95 \%$ CI, 1.45-1.75), age 80 years or more (OR, 1.50; $95 \% \mathrm{CI}, 1.42-1.59$ ), history of atrial fibrillation (OR, $1.30 ; 95 \% \mathrm{CI}, 1.21-1.39$ ), and history of COPD (OR, 1.29; 95\% CI, 1.21-1.36) (Table 3).

\section{DISCUSSION}

In this study, we analyzed the trends in outcomes associated with readmissions among Medicare beneficiaries undergoing isolated CABG from 2000 to 2012. Most important, we found a decrease in 30-day readmission rates, from $19.5 \%$ in 2000 to $16.6 \%$ in $2012(P=.0001)$. After adjusting for increasing comorbidities over time, patients were $28 \%$ less to be readmitted in 2012 than in 2000 . There was a significant trend in improvement across all categories of admission status, age, race, gender, and hospital annual CABG volume examined. Readmission for postoperative wound infections or nonhealing wound decreased significantly $(P=.0001)$. The mortality rate of the readmission episode decreased from $2.8 \%$ to $2.4 \%$ $(P=.0001)$. In addition, length of stay reduced from 5 to 4 days $(P=.0101)$.

Since 2000, there have been significant changes in the healthcare system, changes in the use and application of $\mathrm{CABG}$, and increasing recognition of the importance of readmissions, both as a marker of quality and its financial impact. Our study noted a significant improvement in a number of outcomes pertinent to the discussion of readmissions. In recent years, small reductions in 
TABLE 6. Trends in principle readmission diagnoses after coronary artery bypass grafting

\begin{tabular}{|c|c|c|c|c|c|c|c|c|c|}
\hline Variable & $\begin{array}{c}\text { Overall } \\
(\%)\end{array}$ & $\begin{array}{l}2000 \\
(\%)\end{array}$ & $\begin{array}{l}2002 \\
(\%)\end{array}$ & $\begin{array}{l}2004 \\
(\%)\end{array}$ & $\begin{array}{l}2006 \\
(\%)\end{array}$ & $\begin{array}{l}2008 \\
(\%)\end{array}$ & $\begin{array}{l}2010 \\
(\%)\end{array}$ & $\begin{array}{l}2012 \\
(\%)\end{array}$ & $\begin{array}{c}P \\
\text { value* }\end{array}$ \\
\hline Congestive heart failure & 12.6 & 11.6 & 12.2 & 13.2 & 13.1 & 12.6 & 13.3 & 12.3 & .0001 \\
\hline Postoperative wound infection or nonhealing wound & 8.9 & 9.8 & 9.5 & 9.4 & 9.2 & 7.9 & 7.2 & 6.5 & .0001 \\
\hline Cardiac arrhythmia & 6.4 & 7.1 & 6.6 & 6.1 & 5.7 & 6.3 & 6.3 & 6.5 & .0002 \\
\hline Pleural effusion & 3.7 & 3.6 & 3.8 & 3.5 & 3.6 & 4.0 & 3.9 & 3.7 & .1590 \\
\hline Chronic ischemic heart disease & 3.6 & 3.8 & 4.1 & 3.8 & 3.3 & 3.2 & 3.0 & 2.8 & .0001 \\
\hline Pneumonia & 3.2 & 3.0 & 3.5 & 3.4 & 3.2 & 2.7 & 3.1 & 3.3 & .0560 \\
\hline Ischemic stroke/TIA & 2.9 & 3.8 & 3.2 & 2.7 & 2.4 & 2.4 & 2.3 & 2.3 & .0001 \\
\hline Angina/chest pain & 2.8 & 3.2 & 3.0 & 2.9 & 2.6 & 2.2 & 2.3 & 2.0 & .0001 \\
\hline Postoperative respiratory complications & 2.5 & 2.3 & 2.7 & 2.3 & 2.8 & 2.8 & 2.6 & 2.0 & .4321 \\
\hline Acute MI & 2.3 & 2.3 & 2.6 & 2.3 & 1.9 & 2.3 & 2.3 & 2.0 & .0002 \\
\hline Wound disruption & 1.0 & 1.0 & 0.9 & 0.9 & 1.0 & 1.2 & 1.1 & 1.3 & .0001 \\
\hline GI hemorrhage & 0.7 & 0.6 & 0.6 & 0.7 & 0.8 & 0.8 & 0.8 & 1.0 & .0001 \\
\hline Other procedural complications & 0.7 & 0.7 & 0.7 & 0.9 & 0.8 & 0.8 & 0.5 & 0.5 & .0237 \\
\hline Postoperative hemorrhage/hematoma/seroma & 0.6 & 0.6 & 0.6 & 0.7 & 0.7 & 0.8 & 0.5 & 0.7 & .9409 \\
\hline
\end{tabular}

Percentages reflect the principle diagnosis associated with a readmission for a given year. TIA, Transient ischemic attack; $M I$, myocardial infarction; GI, gastrointestinal. *Cochran-Armitage test for trend across 2000-2012.

readmissions after all hospitalizations have been documented among Medicare beneficiaries. ${ }^{10}$ In an analysis of all Medicare beneficiaries by the CMS, readmission rates were reported at $19 \%$ from 2007 to 2011 , decreasing to $18.4 \%$ in 2012 . In our analysis, the readmission rate for CABG was also $19 \%$ in 2006 , but decreased to $16.6 \%$ in $2012(P=.0001)$, indicating greater improvements for this condition than what would be expected compared with all admissions among Medicare beneficiaries.

The factors that could be contributing to this decline in readmission are likely multifactorial and could be due to better patient care, systems changes, and improved patient selection, and likely other variables that are not be directly related to medical care. Healthcare systems changes that occurred during this study period that may be factors

TABLE 7. Trends in 30-day readmission rate stratified by various baseline/hospital characteristics and year

\begin{tabular}{|c|c|c|c|c|c|c|c|c|c|c|}
\hline Characteristic & $\mathbf{N}$ & Overall $(\%)$ & $2000(\%)$ & $2002(\%)$ & $2004(\%)$ & $2006(\%)$ & $2008(\%)$ & $2010(\%)$ & $2012(\%)$ & $P$ value \\
\hline Acute MI not present & 875,117 & 18.1 & 18.9 & 18.9 & 18.0 & 18.1 & 17.4 & 16.8 & 15.6 & .0001 \\
\hline Acute MI present & 241,874 & 21.8 & 21.8 & 21.5 & 22.4 & 22.2 & 22.1 & 21.0 & 19.7 & .0003 \\
\hline \multicolumn{11}{|l|}{ Admission status } \\
\hline Elective & 324,482 & 15.4 & 16.0 & 16.2 & 15.1 & 15.4 & 15.0 & 14.7 & 13.4 & .0001 \\
\hline Urgent & 755,370 & 20.3 & 20.6 & 20.6 & 20.5 & 20.5 & 20.0 & 19.1 & 18.1 & .0001 \\
\hline Emergency & 37,139 & 21.2 & 21.9 & 21.4 & 21.3 & 21.2 & 19.9 & 21.3 & 18.8 & .0271 \\
\hline \multicolumn{11}{|l|}{ Age, y } \\
\hline$<80$ & 906,779 & 17.8 & 18.5 & 18.4 & 17.8 & 17.7 & 17.3 & 16.6 & 15.7 & .0001 \\
\hline$\geq 80$ & 210,212 & 23.6 & 24.2 & 24.2 & 23.7 & 24.1 & 23.1 & 22.5 & 20.6 & .0001 \\
\hline \multicolumn{11}{|l|}{ Gender } \\
\hline Male & 753,704 & 17.1 & 17.6 & 17.6 & 17.1 & 17.1 & 16.7 & 16.2 & 15.0 & .0001 \\
\hline Female & 363,287 & 22.7 & 23.1 & 23.0 & 22.7 & 23.0 & 22.3 & 21.3 & 20.5 & .0001 \\
\hline \multicolumn{11}{|l|}{ Race } \\
\hline Non-Caucasian & 105,918 & 21.4 & 21.6 & 21.5 & 21.9 & 21.7 & 21.0 & 20.2 & 18.8 & .0001 \\
\hline Caucasian & $1,011,073$ & 18.6 & 19.3 & 19.2 & 18.6 & 18.7 & 18.2 & 17.4 & 16.4 & .0001 \\
\hline \multicolumn{11}{|c|}{ Annual hospital CABG volume } \\
\hline$<50$ & 53,296 & 21.0 & 22.0 & 20.9 & 22.0 & 21.1 & 20.4 & 20.9 & 17.6 & .0001 \\
\hline $50-100$ & 174,016 & 19.1 & 19.8 & 19.8 & 18.9 & 19.1 & 18.8 & 17.9 & 16.8 & .0001 \\
\hline $101-200$ & 382,805 & 18.7 & 19.6 & 19.4 & 18.6 & 18.9 & 18.5 & 17.4 & 16.7 & .0001 \\
\hline$>200$ & 506,874 & 18.8 & 19.1 & 19.2 & 19.0 & 18.7 & 18.0 & 17.5 & 16.4 & .0001 \\
\hline
\end{tabular}

$M I$, Myocardial infarction; $C A B G$, Coronary artery bypass grafting. *Cochran-Armitage test for trend across 2000-2012. 


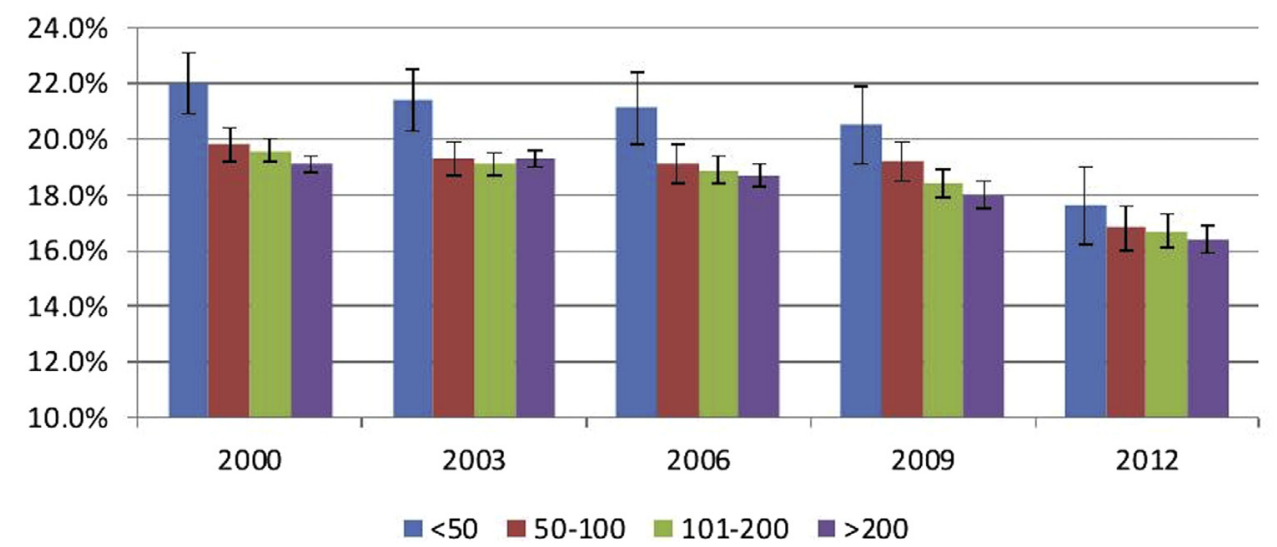

FIGURE 3. Trends in all-cause, 30 -day readmission after CABG stratified by annual hospital CABG volume with $95 \%$ CIs.

include public reporting of readmission data, the HRRP, among others. ${ }^{3-7}$ From a financial perspective, the federal government indicated the possibility of administering penalties on the basis of readmission rates in 2008, which later came to realization in October 2012 with the HRRP, targeting select conditions. ${ }^{5,6}$ Consequently, many healthcare organizations have implemented programs to try and reduce readmissions. ${ }^{7}$ Although financial penalties for excess CABG readmissions would not have occurred during this study period, it is plausible that efforts to reduce readmissions have spanned across multiple conditions or hospital have taken preemptive actions to improve this metric before penalties ensue.

Another potential explanation for the improving outcomes seen in CABG readmission is better patient selection. However, on the contrary, we observed that the comorbidity profiles generally increased significantly over the study period, including the prevalence of hypertension, diabetes, peripheral vascular disease, renal failure, and presentation with acute MI (Table 1). These comorbidities were all associated with an increasing odds of readmission (Table 2). Nevertheless, there are a number of comorbidities not reflected in administrative data that may affect the odds of readmission. In addition, with administrative data, we are unable to obtain detailed angiographic data, so if or how this changed over time is unclear. What these data suggest is that the declining readmission rates are likely not secondary to lower patient risk but probably other factors as previously discussed.

Although we can propose a variety of mechanisms that could account for the reduction in readmission rates in this analysis, it is important to note that a large proportion of readmissions are not preventable and would occur regardless of the care provided. Although estimates vary widely, based on most data, probably at least half of readmissions are not preventable. ${ }^{11}$ A variety of factors, most of which are not due to procedural success or complications, contribute to the odds of readmission. Characteristics such as low socioeconomic status, psychiatric illness, and many other factors that one cannot easily code for with administrative data contribute to the odds of returning to the hospital. ${ }^{12}$ This carries important implications given that the CMS will begin penalizing excess CABG readmissions beginning in 2017, many of which are outside providers' control.

We also examined the causes of readmission and their trends over the study period. Our results from the Medicare database are in agreement with prior statewide and institutional studies in that congestive heart failure, wound infections/complications, cardiac arrhythmias, chest pain, and pleural effusions represent significant causes of readmission after $\mathrm{CABG}{ }^{2,13}$ It should be noted that as a sum of total readmissions, the causes in Table 6 reflect approximately $50 \%$ of total diagnoses. The most common reasons for readmission are included. Considering that any ICD-9 code is a potential primary admission diagnosis, there were numerous causes that accounted for less than $1 \%$, and therefore were not included in our results. The diagnosis with the largest magnitude of reduction was readmission for wound infections/nonhealing wounds, which decreased as a proportion from $9.8 \%$ to $6.5 \%$ $(P=.0001)$. Of note, this includes all operative wounds, including leg and superficial chest wounds, not just sternal wound infections. Given that bilateral internal thoracic artery grafting is a risk factor sternal wound infections, it is important to consider shifts in its use as a potential explanation for the declining wound complications. ${ }^{14}$ However, we have previously published data in the same patient population, which showed increasing use of both the left internal thoracic artery (75.6\% to $88.6 \%$ from $2000-2012)$ and the bilateral internal thoracic artery $(1.8 \%$ to $2.7 \%)$ grafts, so a shift in that bilateral internal thoracic artery use would not appear to explain this finding in regard to nonhealing sternal wounds. ${ }^{8}$ Whether this positive trend is secondary to improved patient education for wound care, better care coordination and follow-up, or other reasons, is unclear. Reductions in readmissions for stroke and cardiac arrhythmias also decreased during the study period. It is plausible that over the previous decade, there has been increasing use of strategies to reduce stroke/transient 
ischemic attack after CABG, such as improved screening modalities and individualized surgical approaches, but this is unable to be confirmed with administrative data. The decrease in readmission for arrhythmias is unlikely to be secondary to a decreasing preoperative incidence, because the opposite has appeared to occur over this period. ${ }^{8}$ We believe this decrease is likely secondary to improved medical management, discharge planning, and a number of other systems factors as previously mentioned.

This study also attempted to delineate various categories of patients/hospital who did or did not benefit from a reduction in readmissions over time. Table 7 demonstrates the trends in readmission rate stratified by the following baseline/hospital characteristics and year: annual hospital CABG volume, acute $\mathrm{MI}$ at the time of index CABG, age $(<80$ and $\geq 80$ years), gender, and race. Irrespective of the category examined, all groups exhibited significant improvements in readmission rates over time (Table 7 , $P<.05$ for all).

Hospital mortality during the readmission was $2.8 \%$ overall. This figure showed a significant downward trend over time, which is encouraging (Table 4). Many predictors of hospital mortality during readmission were the same factors that predicted readmission itself. These factors included a history of renal failure, heart failure, COPD, and atrial fibrillation. Age 80 years or more also was a predictor of hospital mortality during readmission. Hospital mortality during readmission may identify an important set of patients in whom subsequent quality-improvement strategies can be focused. One practical approach would be to have a more targeted return of postoperative patients to where their operation was performed. A recent Medicare analysis of approximately 10 million postoperative patients found that those who were readmitted to the hospital where their procedure was performed had a $26 \%$ lower risk of mortality during their readmission than those readmitted elsewhere. ${ }^{15}$ This makes intuitive sense, because the operating hospital will have streamlined access to all patient information and the perioperative course. Another potential strategy to improve posthospital outcomes would be to direct more intensive follow-up immediately after discharge. Price and colleagues ${ }^{16}$ showed that the majority of post-CABG readmissions occurred within 1 week of the primary hospitalization, with approximately $30 \%$ occurring within 48 hours of discharge. The use of interventions that have been proven to reduce readmissions, such as transition coaches and early physician follow-up, during this immediate posthospital period would be potential strategies. ${ }^{17,18}$

\section{Study Limitations}

Our study should be interpreted in the context of several limitations. It is important to remember that our analysis is of inpatient data only. Inpatient-only data were chosen because this has been the traditionally accepted method of measuring readmissions. ${ }^{6}$ As a result, our analysis does not capture patients who came to the emergency department and were discharged or were under observational status in the hospital. One could argue that the reduction in readmission rate could be secondary to increasing substitution of observation status or discharge from the emergency department; however, current evidence does not support this assertion. A recent article by Zuckerman and colleagues ${ }^{19}$ and an analysis of all Medicare beneficiaries by the CMS studied this topic. ${ }^{20}$ The conclusion of these analyses, which both found slightly declining readmission rates after any hospitalization, was that this reduction was not explained by substitution of observational status or increasing discharge from the emergency department. Specifically, in the analysis by Zuckerman and colleagues, ${ }^{20}$ there was no significant in-hospital association between increasing use of observation status and reduction in readmission rates. However, this was studied after all hospitalizations, not those with a cardiovascular cause specifically, which may affect the results.

There are also limitations to the Medicare database. When using administrative data, coding for certain characteristics changes over time. Thus, it is possible that changes in ICD-9 codes over time could alter causes of readmission. Also, there is concern about the ability of administrative data to properly code for comorbidities and risk stratify patients. Nevertheless, the CMS database has been validated for producing accurate estimates of risk-standardized mortality in comparison with a medical record model in multiple relevant patient populations, including the populations with MI and heart failure. ${ }^{21,22}$ Similar to most administrative data, our model is limited by the inability to include all relevant variables that contribute toward a readmission, such as socioeconomic status, mental illness, and other social factors. Nevertheless, the CMS has chosen not to try and adjust for socioeconomic status because of the concern that doing so may obscure variations in the quality of care vulnerable populations may receive, so our approach is largely consistent with this. ${ }^{9}$ The methodology of determining the urgency of patient admission may have led to misclassification of some patients; however, overall, it was thought that including these data provided additional meaningful risk assessment of patients. In addition, our analysis is limited to patients aged more than 65 years; thus, our results cannot be extrapolated to all patients.

\section{CONCLUSIONS}

The 30-day readmission after discharge from CABG remains common, yet is declining. In a cohort of more than 1 million Medicare patients undergoing CABG from 2000 to 2012 , readmission rates decreased from $19.5 \%$ to $16.6 \%$. This improvement came despite increasing comorbidities over time. The reduction in readmissions was seen regardless of admission status, age, race, gender, and hospital annual CABG volume. Hospital mortality 
associated with readmission declined over the study period, from $2.8 \%$ to $2.4 \%$. Wound complications also decreased over time. The explanations for these encouraging trends are likely multifactorial. Public reporting of the quality measures regarding readmission, CMS initiatives aimed at improving posthospital outcomes, and initial phase of the HRRP appeared during this study period. Together, these strategies may be positively influencing behavior.

\section{Webcast}

You can watch a Webcast of this AATS meeting presentation by going to: http://webcast.aats.org/2016/Video/ Tuesday/05-17-16_Hall_E_1655_Vassileva-800.mp4.

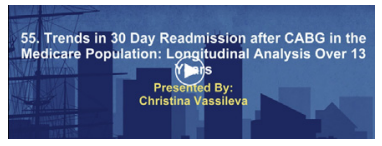

\section{Conflict of Interest Statement}

Authors have nothing to disclose with regard to commercial support.

\section{References}

1. Medicare Payment Advisory Committee. Report to the Congress: Promoting Greater Efficiency in Medicare; 2007. Available at: http://www.medpac.gov/. Accessed July 1, 2017.

2. Hannan EL, Zhong Y, Lahey SJ, Culliford AT, Gold JP, Smith CR, et al. 30-day readmissions after coronary artery bypass graft surgery in New York State. JACC Cardiovasc Interv. 2011;4:569-76.

3. Candidate hospital care additional priorities. 2007 performance measure. Washington, DC: National Quality Forum; 2007.

4. Outcome Measures. Available at: https://www.cms.gov/medicare/qualityinitiatives-patient-assessment-instruments/hospitalqualityinits/outcomemeasures. html. Accessed November 27, 2015.

5. Application of incentives to reduce avoidable readmissions to hospitals. Fed Regist. 2008;73:23673-5.

6. Readmissions Reduction Program. (2014, August 4). Available at: http://cms.gov/ Medicare/Medicare-Fee-for-Service-Payment/AcuteInpatientPPS/ReadmissionsReduction-Program.html/. Accessed August 5, 2015.

7. Bradley EH, Curry L, Horwitz L, Sipsma H, Thompson JW, Elma M, et al. Contemporary evidence about hospital strategies for reducing 30-day readmissions: a national study. J Am Coll Cardiol. 2012;60:607-14.

8. McNeely C, Markwell S, Vassileva C. Trends in patient characteristics and outcomes of coronary artery bypass grafting in the 2000-2012 Medicare population. Ann Thorac Surg. February 29, 2016 [Epub ahead of print].

9. Suter LG, Wang C, Araas M, Joyce E, Vellanky S, Potteiger J, et al. Hospital-level 30-day all-cause unplanned readmission following coronary artery bypass graft surgery—updated measure methodology report. Available at: https://www.cms.gov/ Medicare/Quality-Initiatives-Patient-Assessment-Instruments/HospitalQualityInits/ Measure-Methodology.html. Accessed September 9, 2015.

10. Gerhardt G, Yemane A, Hickman P, Oelschlaeger A, Rollins E, Brennan N. Medicare readmission rates showed meaningful decline in 2012. Medicare Medicaid Res Rev. 2013;3:E1-12.

11. van Walraven C, Bennett C, Jennings A, Austin PC, Forster AJ. Proportion of hospital readmissions deemed avoidable: a systematic review. CMAJ. 2011; 183:E391-402.

12. Joynt KE, Jha AK. Thirty-day readmissions-truth and consequences. $N$ Engl J Med. 2012;366:1366-9.

13. D'Agostino RS, Jacobson J, Clarkson M, Svensson LG, Williamson C, Shahian DM. Readmission after cardiac operations: prevalence, patterns, and predisposing factors. J Thorac Cardiovasc Surg. 1999;118:823-32.
14. Dai C, Lu Z, Zhu H, Xue S, Lian F. Bilateral internal mammary artery grafting and risk of sternal wound infection: evidence from observational studies. Ann Thorac Surg. 2013;95:1938-45.

15. Brooke BS, Goodney PP, Kraiss LW, Gottlieb DJ, Samore MH, Finlayson SR Readmission destination and risk of mortality after major surgery: an observational cohort study. Lancet. 2015;386:884-95.

16. Price JD, Romeiser JL, Gnerre JM, Shroyer ALW, Rosengart TK. Risk analysis for readmission after coronary artery bypass surgery: developing a strategy to reduce readmissions. J Am Coll Surg. 2013;216:412-9.

17. Hernandez AF, Greiner MA, Fonarow GC, Hammill BG, Heidenreich PA, Yancy CW, et al. Relationship between early physician follow-up and 30-day readmission among Medicare beneficiaries hospitalized for heart failure. JAMA. 2010;303:1716-22.

18. Parker C, Griffith DH. Reducing hospital readmissions of postoperative patients with the martin postoperative discharge screening tool. J Nurs Adm. 2013;43:184-6.

19. Gerhardt G, Yemane A, Apostle K, Oelschlaeger A, Rollins E, Brennan N. Evaluating whether changes in utilization of hospital outpatient services contributed to lower Medicare readmission rate. Medicare Medicaid Res Rev. 2014;4.

20. Zuckerman RB, Sheingold SH, Orav EJ, Ruhter J, Epstein A. Readmissions, observation, and the hospital readmissions reduction program. $N$ Engl J Med. 2016;374:1543-51.

21. Krumholz HM, Wang Y, Mattera JA, Han LF, Ingber MJ, Roman S, et al. An administrative claims model suitable for profiling hospital performance based on 30-day mortality rates among patients with an acute myocardial infarction. Circulation. 2006;113:1683-92.

22. Krumholz HM, Wang Y, Mattera JA, Wang Y, Han LF, Ingber MJ, et al. An administrative claims model suitable for profiling hospital performance based on 30-day mortality rates among patients with heart failure. Circulation. 2006; 113:1693-701.

Key Words: coronary artery bypass grafting, readmission

\section{Discussion}

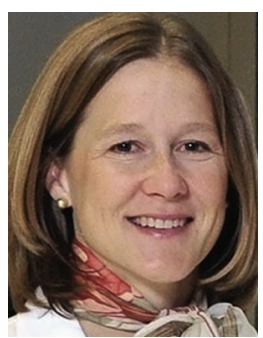

Dr J. Lawton (St Louis, Mo). Your work is particularly valuable in the large number of patients you began with, greater than a million, the fact that you included emergency hospitalizations and isolated CABG only, and the time frame. We like to think of ourselves as thoughtful surgeons, and to take the best care of our patients we use evidence-based medicine, yet with so many quality measures that are now thrust on us, we are now backpedaling almost to demonstrate that the appropriateness of these measures are suitable measures of quality. Because the majority of readmissions are not considered to be preventable, even by Medicare, what do you think the likelihood is that CMS would change these "penalties," if you will, to an incentive model?

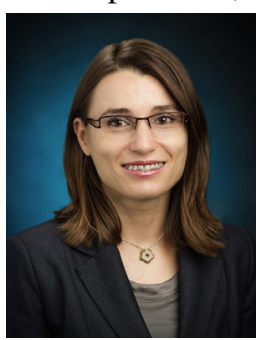

Dr C. M. Vassileva (Springfield, Ill). I think you get to the crux of the issue. We as a community have to figure out what we can prove to the CMS that we can change when we do these operations and what is not going to depend on the surgical care. Now, when we look at the causes for readmission, however, there are multiple entities that can be tied to coordination of care, and all of them may not have anything to 
do with the way the operation was performed or even the early postoperative course. Patients come to the operation with heart failure, and they return to the hospital with heart failure. So recognizing that and using hospital resources to address that in the out-of-hospital setting could be helpful.

Some of these ancillary measures would become important in the future, and I think that perhaps once hospitals get penalized for high readmission rates, that might be a positive incentive to optimize postdischarge care, which could have a significant impact on readmission rates.

Dr Lawton. In an article from our institution authored by Hersh Maniar, we found similar findings. Patients with a lower income and education levels or with no established preoperative care were more likely to be readmitted. I know I have had patients who don't have running water or electricity, and patients without insurance do not get home health care visits. So there are many barriers to patients to comply with health care and to take their medications.

Have these results changed your practice in any way to develop a model or an easily calculated score that we could predict patients who are at risk and maybe have them come back at day 4 or 5 or 7 to see a physician?

Dr Vassileva. I think that I have become more cognizant of the importance of having patients understand the medications that they go home with. They get a list and with all of the reconciliation, I think there is a large percentage of patients who get confused about what they are supposed to take when they go home and we underestimate that, and I think that that partially affects their postoperative recovery. I have not taken any measures to do any quality initiatives at this point, but obviously that's the next step. What I would like to say about outcomes research is it gives us the question and the hypothesis and the possibility of finding a solution, but it doesn't really tell us what to do and how to do it.

Dr Lawton. In your article, you mentioned that there is reduced risk of mortality if the patient returned to the indexed hospital as opposed to an outlying hospital during the repeat hospitalization and a higher readmission rate with lower CABG volume as you had on your last slide.

Could you predict that Medicare in the future might suggest that we have centers of excellence for CABG, that the patients have a reduced rate of readmission because of the higher volume, and if they come back to the same hospital they are more likely to survive their readmission?

Dr Vassileva. That is an interesting question, because when you look at the data on CABG of volume and outcomes, it is mixed. I don't know if the hospital outcome relationship has been well established for CABG, but certainly we did see that hospitals that performed less than 50 operations had high readmission rates. Now, that was only when we compared them with hospitals performing greater than 200 operations. So if we look at 50 versus 100 , there was no difference. So clearly, the more you do the better you are at it, but you have to do a lot more to be better than very little, if that makes sense. And, I'm sorry, what was the other question?

Dr Lawton. Just the centers of excellence.

Dr Vassileva. I don't think there are enough data based on this study to suggest any of that.

Readers who found these articles interesting may also like to read the following papers found in recent and future issues of our sister publications, Seminars in Thoracic and Cardiovascular Surgery and Operative Techniques in Thoracic and Cardiovascular Surgery!

\section{Acquired: Coronary}

ORIGINAL SUBMISSION: Open Aortic Arch Reconstruction After Coronary Artery Bypass Surgery: Worth the Effort? Eduard Quintana. Semin Thoracic Surg 2016:26-35.

Editorial Commentary: Risky Business or Acceptable Risk? Open Arch Repair After Coronary Artery Bypass Surgery. Joseph S. Coselli. Semin Thoracic Surg 2016:36-37.

NEW AND VIEWS: Training in Coronary Artery Bypass Surgery: Tips and Tricks of the Trade. Giuseppe Maria Raffa. Semin Thoracic Surg 2017: In press.

ORIGINAL SUBMISSION: How Safe Is it to Train Residents to Perform Coronary Surgery With Multiple Arterial Grafting? Nineteen Years of Training at a Single Institution. Umberto Benedetto. Semin Thoracic Surg 2017: In press.

Editorial Commentary: Hey! Teacher! Leave Them Kids Alone! Joshua L. Hermsen. Semin Thoracic Surg 2017: In press. ORIGINAL SUBMISSION: Off-Pump Coronary Artery Bypass Grafting. Bobby Yanagawa. Oper Tech Thorac Cardiovasc 2016:2-19. ORIGINAL SUBMISSION: Total Arterial Revascularization. Silvana Marasco. Oper Tech Thorac Cardiovasc 2016: 20-30. 